\title{
Validated HPTLC Method for Simultaneous Estimation of Atenolol and Aspirin in Bulk Drug and Formulation
}

\author{
Vidhya K. Bhusari and Sunil R. Dhaneshwar \\ Department of Pharmaceutical Chemistry, Poona College of Pharmacy, Bharati Vidyapeeth University, \\ Maharashtra, Pune 411038, India \\ Correspondence should be addressed to Sunil R. Dhaneshwar, sunil.dhaneshwar@gmail.com
}

Received 10 October 2011; Accepted 20 November 2011

Academic Editors: W. Misiuk and K. Ohyama

Copyright ( 2012 V. K. Bhusari and S. R. Dhaneshwar. This is an open access article distributed under the Creative Commons Attribution License, which permits unrestricted use, distribution, and reproduction in any medium, provided the original work is properly cited.

\begin{abstract}
This paper describes a new, simple, precise, and accurate HPTLC method for simultaneous estimation of Atenolol and Aspirin as the bulk drug and in tablet dosage forms. Chromatographic separation of the drugs was performed on aluminum plates precoated with silica gel $60 \mathrm{~F}_{254}$ as the stationary phase and the solvent system consisted of n-butanol: water: acetic acid $(8: 2: 0.2 \mathrm{v} / \mathrm{v} / \mathrm{v})$. Densitometric evaluation of the separated zones was performed at $235 \mathrm{~nm}$. The two drugs were satisfactorily resolved with $\mathrm{R}_{\mathrm{F}}$ values $0.23 \pm 0.02$ and $0.72 \pm 0.02$ for Atenolol and Aspirin, respectively. The accuracy and reliability of the method was assessed by evaluation of linearity (100-600 ng/spot for Atenolol and Aspirin), precision (intraday \% RSD was $0.48-1.03$ and interday \% RSD was $0.68-1.14$ for Atenolol, and intraday \% RSD was 0.61-1.03 and interday \% RSD was 0.69-1.04 for Aspirin), accuracy (100.17 \pm 0.32 for Atenolol and $99.73 \pm 0.51$ for Aspirin), and specificity in accordance with ICH guidelines.
\end{abstract}

\section{Introduction}

Atenolol is chemically $(R S)-2-\{4-[2-$ hydroxy-3-(propan-2ylamino)propoxy]phenyl\} acetamide (Figure 1). Atenolol is a beta-adrenergic blocking agent that blocks the effects of adrenergic drugs. The important function of beta-adrenergic stimulation is to stimulate the heart to beat more rapidly. By blocking the stimulation of these nerves, Atenolol reduces the heart rate and is useful in treating abnormally rapid heart rhythms. Atenolol is also helpful in treating angina [1].

Aspirin chemically is 2-acetoxybenzoic acid (Figure 2). Aspirin reduces inflammation, analgesia, prevents clotting, and reduces fever. It is believed to decrease production of prostaglandins and thromboxanes. Aspirin's ability to suppress the production of prostaglandins and thromboxanes is due to its irreversible inactivation of the cyclooxygenase (COX) enzyme. Cyclooxygenase is required for prostaglandin and thromboxane synthesis. Aspirin acts as an acetylating agent where an acetyl group is covalently attached to a serine residue in the active site of the COX enzyme [2].
Today TLC is rapidly becoming a routine analytical technique due to its advantages of low operating costs, high sample throughput, and the need for minimum sample preparation. The major advantage of TLC is that several samples can be run simultaneously using a small quantity of mobile phase unlike HPLC, thus reducing the analysis time and cost per analysis.

Literature review reveals that methods have been reported for analysis of Atenolol and Aspirin by UV spectrophotometry $[3,4]$, method development and validation either alone or in combination with other drugs [5-10], and stability indicating analytical method by HPTLC [11].

To date there have been no published reports on simultaneous quantitation of Atenolol and Aspirin by HPTLC in bulk drug and in tablet dosage form. This present study reports for the first time the simultaneous quantitation of Atenolol and Aspirin by HPTLC in bulk drug and in tablet dosage form. The proposed method is validated as per ICH guidelines [12]. 


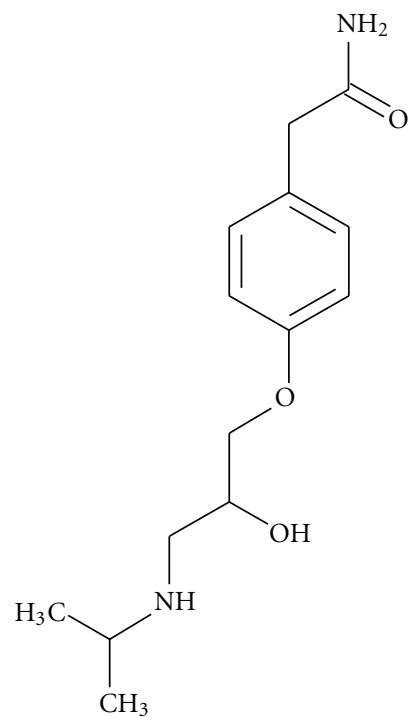

Figure 1: Structure of Atenolol.

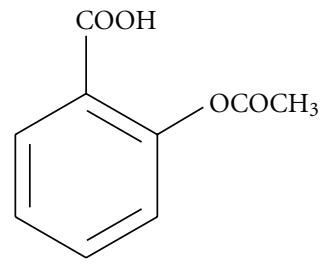

Figure 2: Structure of Aspirin.

\section{Experimental}

2.1. Materials. Working standards of pharmaceutical grade Atenolol (Batch no. 174105) and Aspirin (Batch no. ASI0710032) were obtained as generous gifts from Wockhardt Ltd., Aurangabad (Maharashtra, India). They were used without further purification and certified to contain 99.91\% and $99.90 \%$ (w/w) on dry weight basis for Atenolol and Aspirin, respectively. Fixed dose combination tablets (Brand Name: ATO-PRIN) containing $50 \mathrm{mg}$ of Atenolol and $100 \mathrm{mg}$ of Aspirin were procured from Perk Pharmaceuticals Ltd., Meerut, Uttar Pradesh, India. All chemicals and reagents of analytical grade were purchased from Merck Chemicals, Mumbai, India.

2.2. Instrumentation. The samples were spotted in the form of bands of width $6 \mathrm{~mm}$ with a Camag 100 microlitre sample (Hamilton, Bonded, Switzerland) syringe on silica gel precoated aluminum plate $60 \mathrm{~F}_{254}$ plates $[20 \mathrm{~cm} \times 10 \mathrm{~cm}$ with $250 \mu \mathrm{m}$ thickness; E. Merck, Darmstadt, Germany] using a Camag Linomat V (Switzerland) sample applicator. The plates were prewashed with methanol and activated at $110^{\circ} \mathrm{C}$ for $5 \mathrm{~min}$ prior to chromatography. A constant application rate of $0.1 \mu \mathrm{L} / \mathrm{s}$ was used, and the space between two bands was $6 \mathrm{~mm}$. The slit dimension was kept at $5 \mathrm{~mm} \times 0.45 \mathrm{~mm}$, and the scanning speed was $10 \mathrm{~mm} / \mathrm{s}$. The monochromator bandwidth was set at $20 \mathrm{~nm}$, each track was scanned three times, and baseline correction was used. The mobile phase consisted of n-butanol: water: acetic acid $(8: 2: 0.2 \mathrm{v} / \mathrm{v} / \mathrm{v})$, and $10.2 \mathrm{~mL}$ of mobile phase was used per chromatography run. Linear ascending development was carried out in a $20 \mathrm{~cm} \times 10 \mathrm{~cm}$ twin trough glass chamber (Camag, Muttenz, Switzerland) saturated with the mobile phase. The optimized chamber saturation time for the mobile phase was $30 \mathrm{~min}$ at room temperature $\left(25^{\circ} \mathrm{C} \pm 2\right)$ at relative humidity of $60 \% \pm$ 5. Each chromatogram was developed over a distance of $8 \mathrm{~cm}$. Following the development, the TLC plates were dried in a stream of air with the help of an air dryer in a wooden chamber with adequate ventilation. The flow rate in laboratory was maintained unidirectional (laminar flow, towards the exhaust). Densitometric scanning was performed using a Camag TLC scanner III in the reflectance absorbance mode at $235 \mathrm{~nm}$ and operated by CATS software (V 3.15, Camag). The source of radiation used was deuterium lamp emitting a continuous UV spectrum between 190 and $400 \mathrm{~nm}$. Concentrations of the compound chromatographed were determined from the intensity of the diffused light. Evaluation was performed by linear regression of peak areas determined by UV absorption as a function of sample amounts.

2.3. Preparation of Standard Stock Solutions. Standard stock solutions with a concentration of $1000 \mu \mathrm{g} / \mathrm{mL}$ were prepared in methanol for Atenolol and Aspirin, respectively. From the standard stock solutions, diluted mixed standard solutions were prepared containing $100 \mu \mathrm{g} / \mathrm{mL}$ of Atenolol and $200 \mu \mathrm{g} / \mathrm{mL}$ of Aspirin. The stock solution was stored at $2-8^{\circ} \mathrm{C}$ protected from light.

2.4. Optimization of the HPTLC Method. The TLC procedure was optimized with a view to develop a simultaneous assay method for Atenolol and Aspirin, respectively. The mixed standard stock solution $(100 \mu \mathrm{g} / \mathrm{mL}$ of Atenolol and $200 \mu \mathrm{g} / \mathrm{mL}$ of Aspirin) was taken, and $10 \mu \mathrm{L}$ samples were spotted on to TLC plates and run in different solvent systems. Optimization of HPTLC method was very difficult in this case as both drugs did not move at all. After many trials, it was found that polar mobile phase was required for the movement of both drugs. Hence, n-butanol: water: acetic acid in the ratio of $8: 2: 0.2$ was found optimum (Figure 3 ). In order to reduce the neckless effect, TLC chamber was saturated for $30 \mathrm{~min}$. The mobile phase was run up to a distance of $8 \mathrm{~cm}$, which takes approximately $45 \mathrm{~min}$ for complete development of the TLC plate.

2.5. Validation of the Method. Validation of the optimized TLC method was carried out with respect to the following parameters.

2.5.1. Linearity and Range. From the mixed standard stock solution, $100 \mu \mathrm{g} / \mathrm{mL}$ of Atenolol and Aspirin, 1 to $6 \mu \mathrm{L}$ solution were spotted on TLC plate to obtain final concentration of 100-600 ng/spot for Atenolol and Aspirin. Each concentration was applied six times to the TLC plate. The plate was then developed using the previously described 
TABle 1: Precision studies.

\begin{tabular}{|c|c|c|c|c|c|c|}
\hline \multirow{2}{*}{$\begin{array}{l}\text { Concentration } \\
\text { (ng/spot) }\end{array}$} & \multicolumn{3}{|c|}{ Repeatability $(n=6)$} & \multicolumn{3}{|c|}{ Intermediate precision $(n=6)$} \\
\hline & Measured conc. \pm SD & $(\%) \mathrm{RSD}$ & Recovery (\%) & Measured conc. \pm SD & (\%) RSD & Recovery (\%) \\
\hline \multicolumn{7}{|c|}{ Atenolol } \\
\hline 200 & $198.78 \pm 2.73$ & 0.67 & 99.39 & $199.65 \pm 3.89$ & 1.14 & 99.82 \\
\hline 400 & $400.05 \pm 4.82$ & 0.48 & 100.01 & $394.72 \pm 5.20$ & 0.68 & 98.68 \\
\hline 600 & $599.31 \pm 8.04$ & 1.03 & 99.88 & $601.47 \pm 7.95$ & 0.70 & 100.24 \\
\hline \multicolumn{7}{|c|}{ Aspirin } \\
\hline 200 & $196.61 \pm 3.49$ & 0.61 & 98.30 & $199.83 \pm 3.94$ & 0.69 & 99.91 \\
\hline 400 & $398.32 \pm 5.58$ & 1.03 & 99.58 & $400.78 \pm 5.83$ & 0.83 & 100.19 \\
\hline 600 & $601.77 \pm 8.63$ & 0.72 & 100.30 & $598.36 \pm 8.17$ & 1.04 & 99.72 \\
\hline
\end{tabular}

TABLE 2: Robustness testing.

\begin{tabular}{|c|c|c|c|c|}
\hline Parameter & SD of Peak Area for Atenolol & $\%$ RSD & SD of Peak Area for Aspirin & $\%$ RSD \\
\hline Mobile phase composition $( \pm 0.1 \mathrm{~mL})$ & 6.72 & 1.04 & 12.38 & 1.21 \\
\hline Amount of mobile phase $( \pm 5 \%)$ & 8.94 & 0.97 & 7.82 & 0.78 \\
\hline $\begin{array}{l}\text { Time from spotting to } \\
\text { chromatography ( } 10 \mathrm{~min})\end{array}$ & 9.68 & 0.88 & 10.97 & 0.41 \\
\hline $\begin{array}{l}\text { Time from chromatography to } \\
\text { scanning (10 min) }\end{array}$ & 10.52 & 1.15 & 9.83 & 1.28 \\
\hline
\end{tabular}

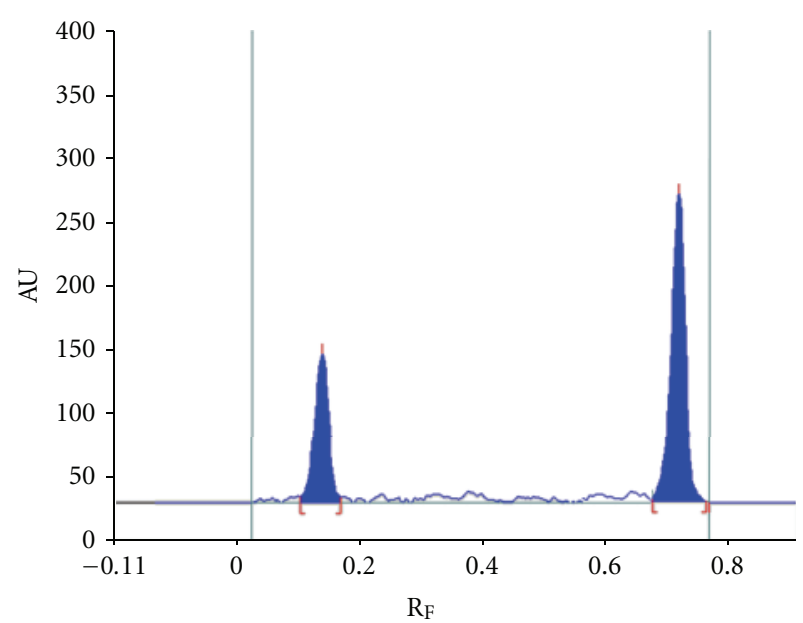

Figure 3: Densitogram of Atenolol $R_{F}(0.23)$ and Aspirin $R_{F}$ (0.72). Mobile phase: $\mathrm{n}$-butanol : water : acetic acid $(8: 2: 0.2 \mathrm{v} / \mathrm{v} / \mathrm{v})$. Concentration of drugs: $100 \mu \mathrm{g} / \mathrm{mL}$ of Atenolol and $200 \mu \mathrm{g} / \mathrm{mL}$ of Aspirin Application volume: $10 \mu \mathrm{L}$.

mobile phase, and the peak areas were plotted against the corresponding concentrations to obtain the calibration curves. Linearity of the method was studied by injecting six concentrations of the drug prepared in the mobile phase in triplicate into the system keeping the injection volume constant. The peak areas were plotted against concentrations to obtain the calibration graphs.

2.5.2. Precision. The precision of the method was verified by repeatability and intermediate precision studies. Repeatability studies were performed by analysis of three different concentrations (200 ng/spot, $400 \mathrm{ng} / \mathrm{spot}$, and $600 \mathrm{ng} / \mathrm{spot}$ for Atenolol and Aspirin) of the drugs six times on the same day. The intermediate precision of the method was checked by repeating studies on three different days.

2.5.3. Limit of Detection and Limit of Quantitation. Limits of detection (LOD) and quantification (LOQ) represent the concentration of the analyte that would yield signal-to-noise ratios of 3 for LOD and 10 for LOQ, respectively. LOD and LOQ were determined by measuring the magnitude of analytical background by spotting a blank and calculating the signal-to-noise ratio for Atenolol and Aspirin by spotting a series of solutions until the S/N ratio 3 for LOD and 10 for LOQ. To determine the LOD and LOQ, serial dilutions of mixed standard solution of Atenolol and Aspirin were performed from the standard stock solution in the range of $10-500 \mathrm{ng} / \mathrm{spot}$. The samples were applied to TLC plate and the chromatograms were run, and measured signal from the samples was compared with those of blank samples.

2.5.4. Robustness of the Method. Following the introduction of small changes in the mobile phase composition $( \pm 0.1 \mathrm{~mL}$ for each component), the effects on the results was examined. Mobile phases having different compositions, for example, n-butanol: water: acetic acid $(8.1: 2: 1 \mathrm{v} / \mathrm{v} / \mathrm{v})$, $(7.9: 2: 1 \mathrm{v} / \mathrm{v} / \mathrm{v}),(8: 2.1: 1 \mathrm{v} / \mathrm{v} / \mathrm{v}),(8: 1.9: 1 \mathrm{v} / \mathrm{v} / \mathrm{v})$, were tried and chromatograms were run. The amount of mobile phase was varied over the range of $\pm 5 \%$. The plates were prewashed with methanol and activated at $110^{\circ} \mathrm{C}$ for 2,5 , and $7 \mathrm{~min}$, respectively, prior to chromatography. The time from spotting to chromatography and from chromatography to scanning was varied from $10 \mathrm{~min}$. The robustness of the method was determined at three different concentration 
TABLe 3: Recovery studies.

\begin{tabular}{|c|c|c|c|c|}
\hline Label claim (mg per tablet) & Amount added (mg) & Total amount (mg) & Amount recovered $(\mathrm{mg}) \pm \% \mathrm{RSD}$ & $\%$ recovery \\
\hline \multicolumn{5}{|c|}{ Atenolol } \\
\hline 50 & $40(80 \%)$ & 90 & $90.26 \pm 0.83$ & 100.28 \\
\hline 50 & $50(100 \%)$ & 100 & $99.74 \pm 1.76$ & 99.74 \\
\hline 50 & $60(120 \%)$ & 110 & $110.56 \pm 0.95$ & 100.50 \\
\hline \multicolumn{5}{|c|}{ Aspirin } \\
\hline 100 & $80(80 \%)$ & 180 & $179.11 \pm 0.65$ & 99.50 \\
\hline 100 & $100(100 \%)$ & 200 & $200.62 \pm 1.18$ & 100.31 \\
\hline 100 & $120(120 \%)$ & 220 & $218.70 \pm 0.96$ & 99.40 \\
\hline
\end{tabular}

TABLE 4: Analysis of commercial formulation.

\begin{tabular}{lcc}
\hline & Mean \pm SD $(n=6)$ & Recovery $(\%)$ \\
\hline \multicolumn{3}{c}{ Atenolol found (mg per tablet) } \\
Atenolol (50 mg) & $50.09 \pm 3.90$ & 100.18 \\
1st Lot & $49.77 \pm 4.11$ & 99.54 \\
2nd Lot & \multicolumn{2}{c}{ Aspirin found (mg per tablet) } \\
Aspirin (100 mg) & & \\
1st lot & $99.73 \pm 6.31$ & 99.73 \\
2nd lot & $99.45 \pm 6.39$ & 99.45 \\
\hline
\end{tabular}

levels for $200 \mathrm{ng} / \mathrm{spot}, 400 \mathrm{ng} / \mathrm{spot}$, and $600 \mathrm{ng} / \mathrm{spot}$ for Atenolol and Aspirin.

2.5.5. Specificity. The specificity of the method was determined by analyzing standard drug and test samples. The spot for Atenolol and Aspirin in the samples was confirmed by comparing the $\mathrm{R}_{\mathrm{F}}$ and spectrum of the spot with that of a standard. The peak purity of Atenolol and Aspirin was determined by comparing the spectrum at three different regions of the spot, that is, peak start $(S)$, peak apex $(M)$, and peak end $(E)$.

2.5.6. Accuracy. Accuracy of the method was carried out by applying the method to drug sample (Atenolol and Aspirin combination tablet) to which known amount of Atenolol and Aspirin standard powder corresponding to 80, 100, and $120 \%$ of label claim had been added (standard addition method), mixed, and the powder was extracted and analyzed by running chromatogram in optimized mobile phase.

2.5.7. Analysis of a Marketed Formulation. To determine the content of Atenolol and Aspirin in conventional tablet (Brand name: ATO-PRIN, Label claim: $50 \mathrm{mg}$ of Atenolol and $100 \mathrm{mg}$ of Aspirin per tablet), twenty tablets were weighed, their mean weight determined, and finely powdered. The weight of the tablet triturate equivalent to $50 \mathrm{mg}$ of Atenolol and $100 \mathrm{mg}$ of Aspirin was transferred into a $100 \mathrm{~mL}$ volumetric flask containing $60-70 \mathrm{~mL}$ methanol, sonicated for $30 \mathrm{~min}$ with occasional shaking, and diluted to $100 \mathrm{~mL}$ with methanol. The resulting solution was centrifuged at $3000 \mathrm{rpm}$ for $5 \mathrm{~min}$, and the drug content of the supernatant was determined $(500 \mu \mathrm{g} / \mathrm{mL}$ for Atenolol and $1000 \mu \mathrm{g} / \mathrm{mL}$ for Aspirin). Then $2 \mu \mathrm{L}$ of the spot was applied which gave final concentration of $1000 \mathrm{ng} / \mathrm{spot}$ for Atenolol and $2000 \mathrm{ng} / \mathrm{spot}$ for Aspirin. The TLC plate was then developed in optimized mobile phase. The analysis was repeated in triplicate. The possibility of excipients interference with the analysis was examined.

\section{Results and Discussion}

The results of validation studies on simultaneous method developed for Atenolol and Aspirin in the current study involving n-butanol: water:acetic acid $(8: 2: 0.2 \mathrm{v} / \mathrm{v} / \mathrm{v})$ as the mobile phase for TLC are given below.

3.1. Linearity. The drug response was linear $\left(R^{2}\right.$ of 0.9977 for Atenolol and 0.9981 for Aspirin) over the concentration range between 100 and $600 \mathrm{ng} / \mathrm{spot}$ for Atenolol and Aspirin, respectively.

3.2. Precision. The results of the repeatability and intermediate precision experiments are shown in Table 1. The developed method was found to be precise as the RSD values for repeatability and intermediate precision studies were $<2 \%$, as recommended by ICH guidelines.

3.3. LOD and LOQ. Signal-to-noise ratios of $3: 1$ and $10: 1$ were obtained for LOD and LOQ, respectively. The LOD and LOQ were found to be $80 \mathrm{ng} / \mathrm{spot}$ and $100 \mathrm{ng} / \mathrm{spot}$ for Atenolol and Aspirin, respectively.

3.4. Robustness of the Method. The standard deviation of peak areas was calculated for each parameter, and the \% RSD was found to be less than 2 . The low values of the $\%$ RSD, as shown in Table 2, indicated the robustness of the method.

3.5. Specificity. The peak purity of Atenolol and Aspirin was assessed by comparing their respective spectra at the peak start, apex, and peak end positions of the spot, that is, $r(S, M)=0.9971$ and $r(M, E)=0.9973$. A good correlation $(r=0.9989)$ was also obtained between the standard and sample spectra of Atenolol and Aspirin, respectively. 
3.6. Recovery Studies. As shown from the data in Table 3, good recoveries of the Atenolol and Aspirin in the range from 99.40 to $100.50 \%$ were obtained at various added concentrations.

3.7. Analysis of a Formulation. Experimental results of the amount of Atenolol and Aspirin in tablets, expressed as a percentage of label claims, were in good agreement with the label claims thereby suggesting that there is no interference from any of the excipients which are normally present in tablets. Two different lots of Atenolol and Aspirin combination tablets were analyzed using the proposed procedures (Table 4).

\section{Conclusion}

Introducing TLC into pharmaceutical analysis represents a major step in terms of quality assurance. The developed TLC technique is precise, specific, and accurate. Statistical analysis proves that the method is suitable for the analysis of Atenolol and Aspirin as bulk drug and in pharmaceutical formulation without any interference from the excipients. It may be extended to study the degradation kinetics of Atenolol and Aspirin, also for its estimation in plasma and other biological fluids. The proposed TLC method is less expensive, simpler, rapid, and more flexible than HPLC.

\section{Acknowledgments}

The authors would like to thank Wockhardt Ltd. (Aurangabad, Maharashtra, India) for providing a gift sample of standard Atenolol and Aspirin. They would like to thank Dr. K. R. Mahadik, the Principal, Poona College of Pharmacy, Pune, India, for providing necessary facilities to carry out the work.

\section{References}

[1] http://www.medicinenet.com/atenolol/article.htm.

[2] http://en.wikipedia.org/wiki/Mechanism_of_action_of_aspirin.

[3] A. V. Kasture and M. Ramteke, "Simultaneous UV-spectrophotometric method for the estimation of atenolol and amlodipine besylate in combined dosage form," Indian Journal of Pharmaceutical Sciences, vol. 68, no. 3, pp. 394-396, 2006.

[4] A. Gölcü, "New, simple, and validated UV-spectrophotometric method for the estimation of some beta blockers in bulk and formulations," Journal of Analytical Chemistry, vol. 63, no. 6, pp. 538-543, 2008.

[5] A. P. Argekar and S. G. Powar, "Simultaneous determination of atenolol and amlodipine in tablets by high-performance thin-layer chromatography," Journal of Pharmaceutical and Biomedical Analysis, vol. 21, no. 6, pp. 1137-1142, 2000.

[6] P. V. Deore, A. A. Shirkhedkar, and S. J. Surana, "Simultaneous TLC-Densitometric analysis of atenolol and lercanidipine hydrochloride in tablets," Acta Chromatographica, vol. 20, no. 3, pp. 463-473, 2008.

[7] A. K. Sharma, B. Shah, and B. Patel, "Simultaneous estimation of Atorvastatin calcium, Ramipril and Aspirin in capsule dosage form using HPTLC," Der Pharma Chemica, vol. 2, pp. 10-16, 2010.
[8] H. A. Panahi, A. Rahimi, E. Moniri, A. Izadi, and M. M. Parvin, "HPTLC separation and quantitative analysis of aspirin, salicylic acid, and sulfosalicylic acid," Journal of Planar Chromatography: Modern TLC, vol. 23, no. 2, pp. 137-140, 2010.

[9] A. Y. Kamble, M. V. Mahadik, L. D. Khatal, and S. R. Dhaneshwar, "Validated HPLC and HPTLC method for simultaneous quantitation of amlodipine besylate and olmesartan medoxomil in bulk drug and formulation," Analytical Letters, vol. 43, no. 2, pp. 251-258, 2010.

[10] R. Kakde and N. Bawane, "High-performance thin-layer chromatographic method for simultaneous analysis of metoprolol succinate and amlodipine besylate in pharmaceutical preparations," Journal of Planar Chromatography: Modern TLC, vol. 22, no. 2, pp. 115-119, 2009.

[11] M. C. Damle, P. K. Sinha, and K. G. Bothra, "A validated stability indicating HPTLC method for determination of aspirin and clopidogrel bisulphate in combined dosage form," Eurasian Journal of Analytical Chemistry, vol. 4, pp. 152-160, 2009.

[12] "Validation of analytical procedures: text and methodology Q2 (R1)," in Proceedings of the International conference on harmonization (ICH '05), Geneva, Switzerland, 2005. 


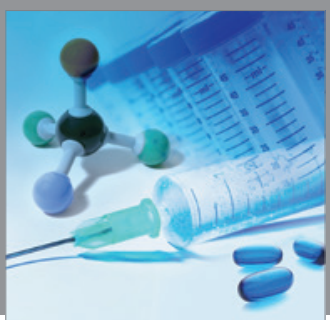

International Journal of

Medicinal Chemistry

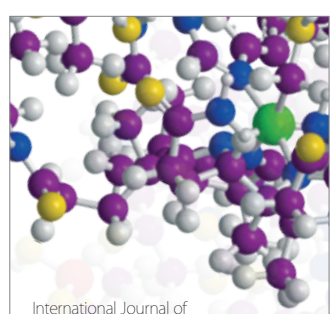

Carbohydrate Chemistry

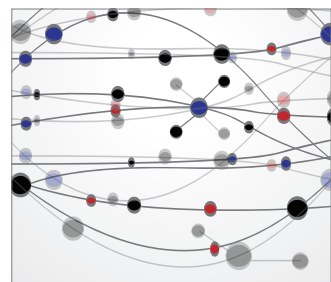

The Scientific World Journal
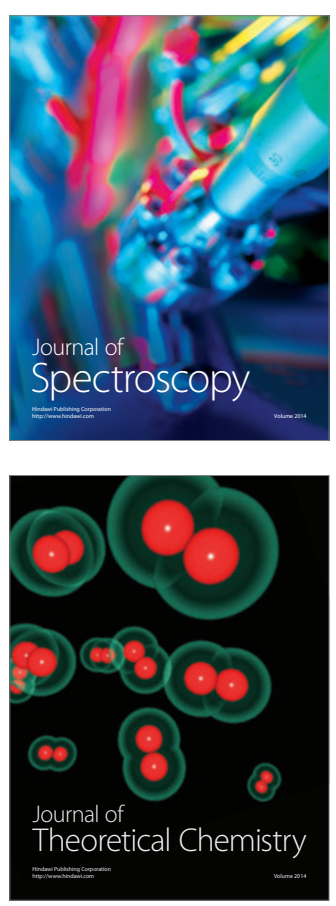
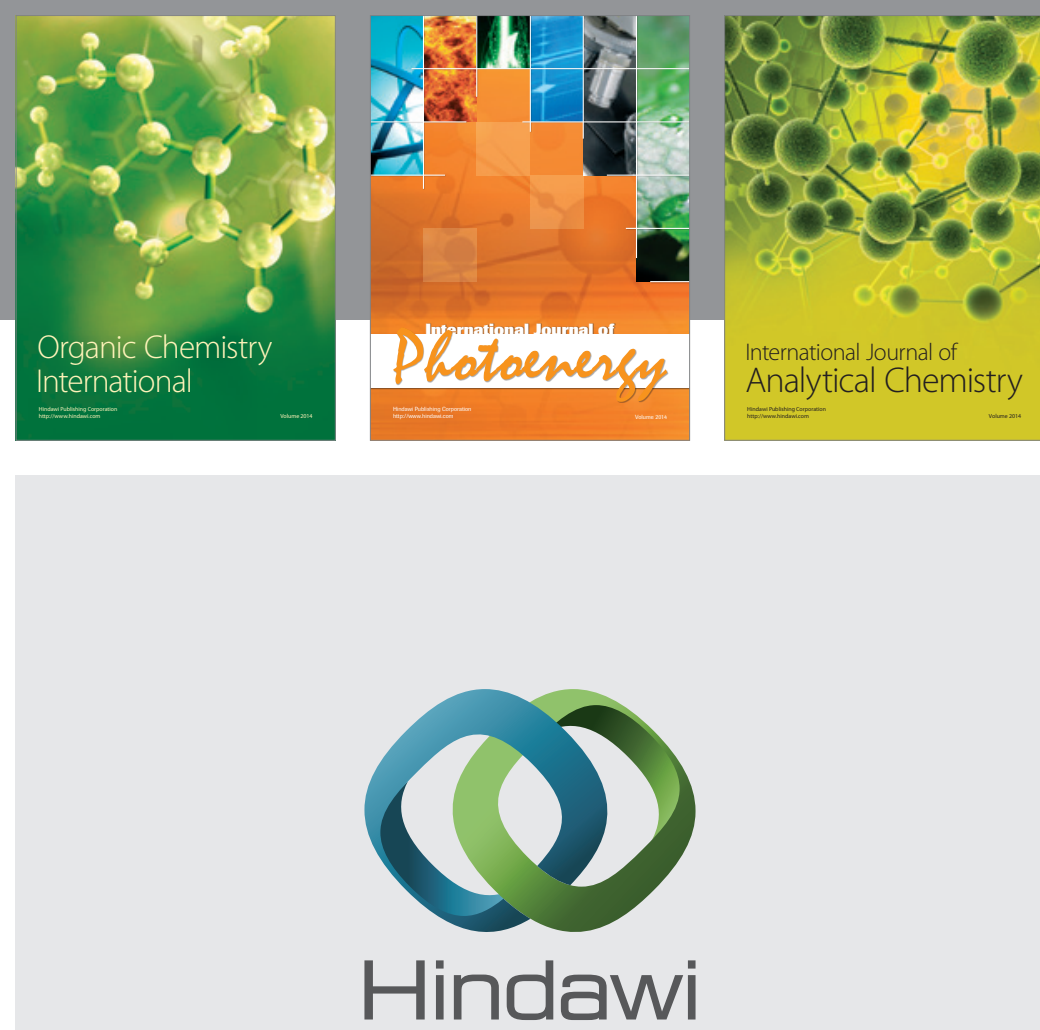

Submit your manuscripts at

http://www.hindawi.com
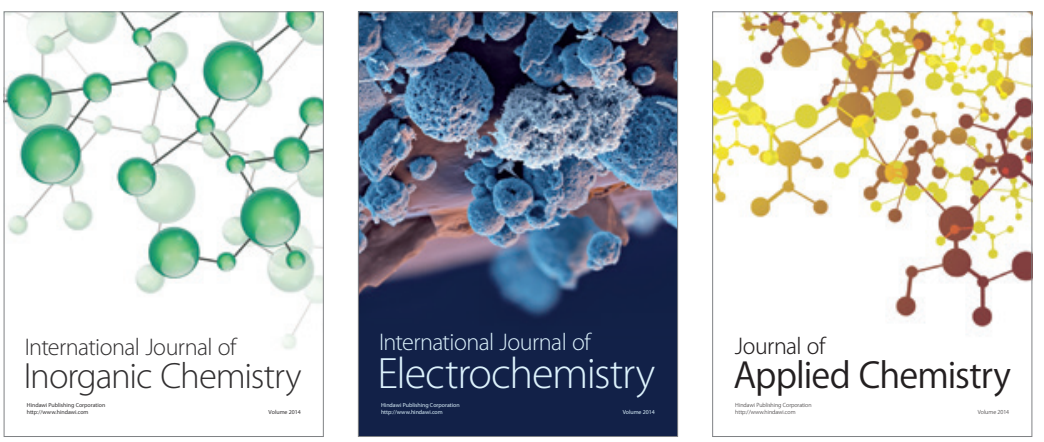

Journal of

Applied Chemistry
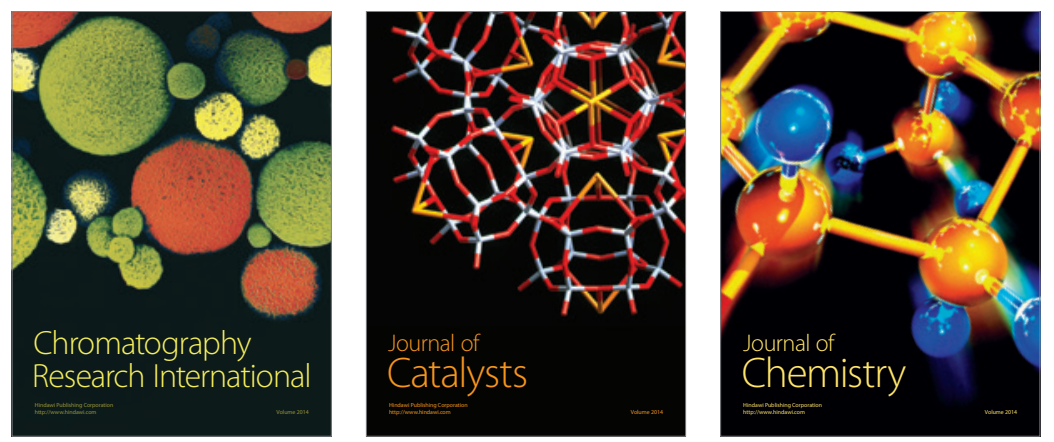
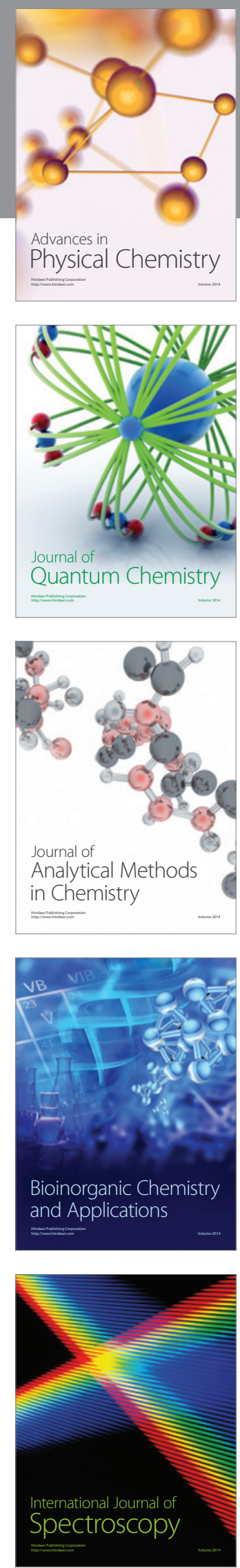